\title{
Investigation of L2 Learners' Reading Attitudes with an Impact of Extensive Reading Project at Secondary Level, Sindh, Pakistan
}

\author{
Dania Wasi Khan \\ M.S Scholar (Applied Linguistics) at English Language Development Centre \\ Mehran University of Engineering \& Technology, Jamshoro, Pakistan \\ Shumaila Aijaz Memon \\ Associate professor at English Language Development Centre \\ Mehran University of Engineering \& Technology, Jamshoro, Pakistan
}

\begin{abstract}
The research is Self-financed
Abstract

In Pakistan, English is most importantly taught at all levels of education and several subjects are taught through the medium of English. Students acquire much of knowledge by reading written literature. Therefore, the importance of reading is inevitable at school level where students have to develop and adopt several strategies and new skills. Reading attitude is a complicated notion, and has a crucial role in developing reading skill. Reading attitudes are based on past experiences and practices and make a learner to be positive or negative for attempting the reading activity. Several researches suggest that learners' choice for reading material and flexibility add a vital role in shaping the reading attitudes of the learners. Therefore, this study had taken the extensive reading for the instruction to gain support for the reading attitudes in second language. This attempt was made to fill the gap by investigating the effectiveness of extensive reading on the L2 reading attitudes. The subjects were 110 secondary level learners from Sindh, Pakistan. A reading attitude likert scale questionnaire was used before and after the 12week project of extensive reading with 20 items divided into 6 variables: self-perception, intellectual value, practical value, linguistic value, comfort and anxiety. The results were compiled with the help of SPSS analysis, that showed the descriptive analysis of both pre and post project reading attitudes for each variable and significant difference. Suggestions and implications are highlighted for future practices and research.
\end{abstract}

Keywords: Extensive reading, Reading attitude, Second Language, Learners' Choice

DOI: $10.7176 /$ RHSS/11-2-06

Publication date: January $31^{\text {st }} 2021$

\section{Introduction}

Reading is an ability, required by all learners. There should be opportunities to fulfill learners' need to improve their performances. But, there is a factor which is always encountered by a language teacher among the students at the secondary level, they pay attention towards the activities which focus other language skills and their attitudes show less interest and boredom when it comes to reading activities. Given this problem, it was of interest to study reading attitudes with an effect of a strategy which should be different from the traditional practices for the students of secondary level in Sindh, Pakistan. Researcher gets the motivation by the thought that there should be a balanced approach by focusing on different language developmental process and reading skills equally. The exposure to reading should be tried extensively to encourage students' motivation and teacher himself should be the part as a practitioner. Therefore, in the present study the researcher considered ER to investigate it as a supplement to gauge students' attitude and to check this ER practice as an alternative approach.

\subsection{Reading Attitude}

Attitude is a complicated notion, which is referred as "a learned predisposition to respond in consistently favorable or unfavorable manner with respect to a given object" (Fishbein and Ajzen, 1975, p.6, cited in Mckenna, 1994). Reading attitude with reference to the above definition is an opinion or feeling to reading which makes learner to be positive or negative for attempting the reading activity. When we come to the second language learning affective factors as compared to the cognitive factors are less highlighted, though the readiness to learn and get involved in certain activity has a crucial role. Grabe and Stoller, (2002), suggest that Students' previous experiences, exposure and perception about reading construct their attitudes towards reading activities. Day and Bamford (1998) presented the model of acquisition and development of 12 reading attitudes, one of the sources presented by this model explains that the material and attitude of the learner towards reading affect the learners' desire to read, it is observed that due to unwanted material students bear negative attitudes and show boredom. The above ideas reflect that reading attitude being a complex phenomenon affects and readers' experiences of different favorable or unfavorable conditions shape their reading attitudes. 


\subsection{Extensive Reading}

Extensive reading is one of the important approaches of teaching and learning second language reading skills, where students experience a number of books or other materials that consider the choice of learners within their language competency, ( Day and Bamford, 1998). Extensive reading is very much influential in convincing young students to read in the English language and to be positive towards reading activities, which increases motivation of learners. The positive second language attitudes can be promoted by successful reading programs, these programs help and motivate learners to continue reading practices ( Day and Bamford, 1998, Yamashita, 2013). Leisure reading is taken as "reading of any kind excluding school texts and other materials assigned at school". (Greaney, 1980; 345). Jacob and Gallo (2002) suggest that reading is something enjoyable. Kamhieh (2012) coined the notion that, "Leisure or extensive reading relates to enjoyment". According to Krashen (2004) it is free voluntary reading that makes readers feel free for selecting what to read and not to look for complex processes of finding meaning and extraction of information. These all studies mentioned that purpose is an important factor which can be enjoyment, that can only be done by the choice of learners in respect of reading material.

\section{Literature Review}

Nutall (1996) observed extensive reading in comparison to intensive reading helps to read for the sake of reading itself not for the sake of mastery of a particular language structure. Nutall (2005) stated the solution of the reading problems through the cycle of frustration and growth. According to that one of the main principle characteristics of a good reader is "flexibility". A reader changes speed and way of reading as per text and his motive of reading it and he described ER as "the easiest and most effective way to improve students' skills" (p. 127) and claimed that it is "much easier to teach people to read better if they are learning in a favourable climate" (p. 127).

Chang and Renandya,(2017), investigated one hundred and nineteen L2 teachers in the context of Asia through an online questionnaire about the reason for implementing ER, it's difficulties and perception of its effectiveness, the results show that teachers had strong positive beliefs in the effectiveness of ER in improving students' competence of language but there were few students and teachers related difficulties which were reported regarding the program. They concluded with the suggestion of the balanced approach for ER implementation which could help in implementing ER program effectively and efficiently.

7weeks ER program was implemented by Hardy in 2016, in US University, attitudes and motivation were investigated through pre and post treatment questionnaire, the results showed that ER program helped to increase self-efficiency in L2 and intrinsic motivation. Chien and Yu (2015) investigated a primary research on Taiwanese University fresh students, they administered an ER project for one year on 60 students, the questionnaire was administered, and findings revealed ER improved participants' cognitive attitudes of reading in L2.

Ro and chen (2014) presented their primary study that was the replica of Camiciottoli (2001), they investigated 60 ESL adult learners' attitudes towards reading extensively in US University, they used the questionnaire as an instrument, study reveals the result that learners with positive attitudes towards L2 reading read more in L2, likewise Robb and Kano (2013) found out the impact of ER by motivating less motivated Japanese EFL students, findings show that the more evaluative component of ER, the more L2 learners will read.

Systematic comparative studies were many as well, which preferred attitude questionnaire to know the attitudes of learners with an effect of ER. For example: A quasi experimental study in Korea was conducted by Young A Park (2017), to compare ER and IR approaches on EFL learners' reading rate and comprehension, the time period for the treatment was 12 weeks, 72 Korean secondary level students were the participants in total, the researcher divided the students into two groups for the instruction of ER and IR separately, pre and post tests were conducted to gather data in the form of performance. ANCOVA results revealed that students from ER group significantly increased their reading rate in comparison to IR group.

Lao and Krashen (2000) conducted a research on a group of readers who were exposed to literature based pleasure reading and other one with the traditional pedagogy of four skills. The first group outperformed that was obvious in reading skills as they had reading of a novel for pleasure. Robb and Susser (1989) had the comparison of two classes with the difference of traditional and ER teaching practices for reading skills, which resulted with the outclass performance of ER class in form of attitudes and motivation as they enjoyed reading.

The studies mentioned above concluded the different ways of conducting extensive reading program, and every study out of these has come up with some different result. The overall it suggests that second or foreign language teachers with respect to their different contexts and courses have to adopt and implement extensive reading in this respect. Some teachers bound the activity to be held within the class only some give reading tasks for homework which is considered as reading outside the classroom, some of them select the practice in both ways outside and in the classrooms. For monitoring the program they adopt certain activities to have check and balance of reading of the learners, such as, through quizzes, by writing book reports, delivery of presentations, etc. some teachers don't even consider such activities and they allow their learners to go without attempting any certain activity after the task. These different implementations and ways of conducting extensive reading goes to the different and varied outcomes, as it is shown in the studies mentioned above. On the whole, results of all studies 
conclude that students held their views in a positive direction for the practices of extensive reading, but yes, another point can be concluded that learners didn't seem to assume extensive reading as their first priority for their learning. This urges the need for more research in this area. There are few who have worked on its impact on reading attitudes. Out of those most of the work is done on EFL and conducted in countries other than Pakistan, especially in Japan. Mostly the participants were taken from university first year or college students. Less concerns were found in Pakistan regarding implementing ER projects in school systems. Researcher has found that there is a lack of research on reading attitudes with an effect of the Extensive reading project in Pakistani context especially at school level students.

\subsection{Research Questions}

1. What are the attitudes of secondary level learners towards reading in English, before experiencing extensive reading project in Sindh, Pakistan?

2. What are the attitudes of secondary level learners towards reading in English, after experiencing extensive reading project in Sindh, Pakistan?

\section{Methodology}

This study follows the quantitative research approach. Quantitative research is a systematic investigation of any phenomena, in this study researcher has gathered quantifiable data and performs statistical techniques. This quantitative research approach has collected information from sample using questionnaire and results are depicted in the form of numerical. These numbers are carefully understood and analysed by researcher to predict the results..

\subsection{Participants}

The participants of this study were 110 secondary level learners of English medium private schools in Sindh, Pakistan. The students came from different backgrounds of different languages. Participants were selected through stratified random sampling, where they were randomly selected from the groups made on the basis of their performance in academics. Students were enrolled in academic year 2019-20 with the medium and low level of proficiency in the English language.

\subsection{Instrument}

Questionnaire as an instrument with the construction of various items easily gather the data within less consumption of time, due to this advantage researcher considered the questionnaire as the tool for this research. The data was gathered from participants about reading attitudes. Closed ended questions were used to get straightforward coding and tabulation which was suitable for the level of participants, as it is quicker and easier to answer. There were 6 variables and 20 items, Self-perception as a reader(4 items), Intellectual value (3 items), Practical value ( 3 items), linguistic value( 3 items), comfort ( 4 items), and reading anxiety( 3 items). The questionnaire was adapted from the study of S, Memon (2014). The five point likert scale was used to measure attitudes, as its reliability is good due to the vast range of responses. The points of likert scale ranged from strongly agree to strongly disagree.

\subsection{Procedure}

The data was collected through pre and post ER project questionnaires. Selected students for the study were given a questionnaire to fill in a formal setting before conducting ER project to check the attitudes towards reading before the treatment of ER. Then treatment of ER was given to the students for 12 weeks by providing treatment material to choose one after finishing the previous material. Bamford (1998) suggests that students need motivation to achieve the goal. Total reading was assigned for 12 weeks as the goal. There are a number of ways that can be followed for ER project. This study followed the supervised ER project. This was taken place in school, where according to RO'E (2013) the researcher himself works as a participant's mentor and sits with them. 30 minutes class, 4 classes per week for the total 12 weeks time period in total were scheduled. They were asked to give a review of each material after completing it in the form of different activities. After the completion of the extensive reading project, post the ER project questionnaire was administered to investigate the reading attitudes towards ER and to find out the reading attitudes with an effect of ER practice.

\subsection{Treatment material:}

100 graded readers were selected from several publishers (such as Penguin Readers, Oxford University Press, and Cambridge University Press) along with the magazines and articles of students' interest. Students were allowed to be free to choose material with the guidance of the researcher. Text difficulty level and students' interest were considered. The material was classified into five levels in accordance to the difficulty level. Each was presented with in the categorized level. Students selected the reading material as per their reading ability and ease by considering the levels set by the researcher. The readability level was 200-1500 words as per proficiency level of 
students

\subsection{Analysis}

The instrument was reading attitude questionnaire; the reliability for the instrument was checked through Cronbach Alpha coefficient. The gathered pre data collected by the researcher was found to have .706 Alpha value, and the post data was found to have .732 Alpha value. The value of reliability for the instrument was satisfactorily reliable. That was checked to measure If all the items in the reading attitude questionnaire for the variable reading attitudes construct the internal consistency or not. The total item correlation was varied from .25 to .487 , that indicated the strong correlation between the items of reading the questionnaire. Hence the data was considered for all the questions and used further statistical analysis. This study followed the quantitative method, quantifiable pre and post data were analysed with the help of descriptive analysis by calculating the mean and standard deviation of each variable later the difference of reading attitudes was calculated by running the paired sample $t$ test of overall means of both data. Responses were coded with the range of 1 to 5 the to run statistical analysis, few items of variables such as self-perception, comfort and anxiety were reported negatively, hence coded reversely. Interpretation was done on the basis of mean ranges and significant value.

\section{Result}

The results of this study based on the descriptive analysis of two sets of pre and post ER project attitudes, further the significant difference is calculated by running the paired sample t-test. The findings show that the reading attitudes of students before experiencing the extensive reading project are ranged towards the low and moderate levels for different variables set for the attitude values, while after the impact of extensive reading project the attitudes are different and range is increased for each variable and marked as moderate and high levels. The overall mean for pre data is calculated 2.61 and for post data 3.67.

Table No. 4.1 Descriptive Analysis of Pre and Post ER project Reading Attitudes on the basis of Individual Variable.

\begin{tabular}{|c|c|c|c|c|c|c|c|c|c|}
\hline \multicolumn{5}{|c|}{$\begin{array}{l}\text { Descriptive analysis of pre data for reading } \\
\text { attitudes }\end{array}$} & \multicolumn{5}{|c|}{$\begin{array}{l}\text { Descriptive analysis of post data for reading } \\
\text { attitudes }\end{array}$} \\
\hline Variables & $\mathbf{N}$ & Mean & SD & Value & Variables & $\mathbf{N}$ & Mean & SD & Value \\
\hline $\begin{array}{l}\text { Self- } \\
\text { perception }\end{array}$ & 110 & 2.56 & .4623 & Moderate & Self-perception & 110 & 3.51 & .4273 & High \\
\hline Intellectual & 110 & 2.85 & .7342 & Moderate & Intellectual & 110 & 3.89 & .4878 & High \\
\hline Practical & 110 & 2.95 & .5557 & Moderate & Practical & 110 & 3.94 & .3636 & High \\
\hline Linguistic & 110 & 2.99 & .5738 & Moderate & Linguistic & 110 & 4.01 & .3826 & High \\
\hline Comfort & 110 & 2.30 & .7017 & Low & Comfort & 110 & 3.70 & .4600 & High \\
\hline Anxiety & 110 & 2.10 & .4811 & Low & Anxiety & 110 & 3.03 & .4463 & Moderate \\
\hline
\end{tabular}

The differences in attitudes for the self-perception value shows the mean difference of 0.95 , indicates the shift from moderate level to the high level of attitudes. Intellectual value calculates the mean difference of 1.03 , that is a positive number, indicates the positive change from moderate to high level attitudes. For the practical value, the difference is calculated as 0.98 that indicates the change in attitudes from moderate level to high level. The mean difference for the linguistic value is calculated as 1.02. That indicates the change in attitudes from moderate to high. The comfort value is also increased from low to high level and calculates the mean difference 1.40, that indicates the positive change. Reading anxiety is calculated 0.93 as the value of the mean difference that indicates the change in attitudes from Low to moderate level.

Table No. 4.2 Comparative Analysis of Mean Difference for the Measurement of Significant Difference

\begin{tabular}{|l|l|l|l|l|l|}
\hline \multirow{2}{*}{ Overall test score pre-post } & Mean diff & Standard deviation & t-value & Df & Sig(2 tailed) \\
\cline { 2 - 7 } & -1.06955 & .30373 & -36.932 & 109 & .000 \\
\hline
\end{tabular}

The overall mean score for pre ER project reading attitudes is calculated 2.61 which later has increased to 3.67. Moreover, the statistical analysis indicates that there is a significant difference for each variable. The analysis favors the reading attitudes gathered in post data. These results indicates the positive change in reading attitudes with an effect of 12 week extensive reading project calculating the $\mathrm{t}(109)=-36.932, \mathrm{P}<.001$.

\subsection{Discussion}

The present study investigates the reading attitudes with an impact of 12 week ER project with the help of 6 variables. The results ensure the effectiveness of ER for each variable of reading attitudes after 12 weeks. The analysis favors the reading attitudes gathered in post data are significantly positive with the mean difference of 1.068 , and $\mathrm{p}<.001$. 
The results of the pre data are in between low to moderate level for each variable. That indicates that students were not holding the positive attitudes towards reading in English. The purpose of conducting the pre data was to determine the attitudes without practicing any new teaching strategy, and to check the set attitudes based on the previous learning and teaching methods. Hence, the previously set attitudes were based on the past practices and experiences that the students encountered. Those were not presented to highlight the importance of the skill itself. Therefore, the values of intellectual and practical purposes were measured moderate in pre data. Students took less interest in reading activities as they found it not so worthy of their betterment. They didn't think reading in English was as important for practical and intellectual purposes and found a moderate impact of it on their intellectual growth and future achievements. They thought as per mind set they got from past experiences and set examples, which shaped their attitudes up to this level. On the other hand after ER practice, the responses for intellectual and practical values for the reading attitudes are found high. That indicates the positive impact of extensive reading for considering the relation to reading in English with the intellectual and practical growth. That can be calculated in the account of motivation to reading. This result partially agrees with the literature, (Hardy 2016) suggested highly favorable reactions to extensive reading that, self efficiency in L2 and intrinsic motivation can be increased effectively with ER but extrinsic motivation hadn't positive results. But in this study, extrinsic purposes in the form of intellectual and practical growth have also been influenced positively.

The traditional methods of teaching reading skills have set the criteria for reading activities and practices to be bound with particular text and chapters already set in the syllabus. The room for the learners' choice has been removed. These traditional pedagogical techniques have made the mind set of learners not to show consideration of their choices for the reading text as they were never asked for that. That showed the results in the form of low comfort and high reading anxiety in pre data. Jacob and Gallo (2002) suggest that reading is something enjoyable. Kamhieh (2012) coined a notion, Leisure or extensive reading relates to enjoyment. In the light of reviewed literature, the learners' feeling of comfort can be improved by initiating the effective ways of teaching reading that can make learners feel comfortable and to express their choices. The selected material for reading of learners' choice can only make them feel free and to consider the process enjoyable. The results of this study completely agree with the above finding as the comfort value is increased and anxiety value is decreased with an impact of extensive reading project, where students are free to choose the material of their interest. This result for comfort and anxiety correlates with the findings of Robb and Susser (1989) suggested the results with the outclass performance of ER class in the form of attitudes and motivation as students enjoy reading. They find themselves free to choose their texts for reading which helps them increase their interest

The value of self-perception as a reader indicated in the per data that the learners didn't feel free to express their choice and to consider themselves as a good reader that also contributed to the confidence level. Students set values and beliefs on the basis of their past experiences which affect their attitudes. The data gathered on the basis of traditional practices proved the lack in strategies and practices set in the past. It is naturally assumed that having control on an action you do, provides you more confidence, same is the case with students, they love to or be more willing towards engaging themselves in an activity where they have control. That will help them to contribute to their overall language performance, relating the study of Strauss et, al (2014) that suggests "acquiring the dependency of turning to books for nothing but pleasure and to discover what is the learners' desire to comprehend on his own do more than emphasizing on fluency or decoding of words. No matter what you impose and how much a teacher imposes that has no impact if the student doesn't have confidence and ease. By emphasizing on large text with the focus of achieving set goals impacts nothing but a pressure higher than the students' knowledge.

The overall findings of this study suggest that "extensive reading help learners become autonomous", as Yamashita (2013) suggested that "for the development of reading abilities it is required to have reading autonomy". That increase the confidence level of learners and involve them in the process. The reading attitudes with an impact of the extensive reading project are found positive, it has not only motivated students but they read more and more though they get less time for reading in class. But the impact of the material selection and no set complex process has given them a chance to develop their interest positively for all variables set for reading attitudes. This whole process has motivated students to enter in the virtuous cycle of the good reader as noted by Nutall (2005).

\section{Conclusion}

The study concludes that, positive feelings towards reading can be fostered through ER. Indeed, it can enhance the decisions of learners to read and improve their reading attitudes. This change in attitudes marked as the ease students feel due to a free hand for the selection of material and flexibility towards the reading process . Finding correlates with the literature and suggests "engaging learners in the reading activity is the solution but the strategies and practices need to be improvised".

\subsection{Suggestions}

Reading is the way we become a reader, avoiding the task is not a solution. Little efforts from the teacher and 
students can bring great changes. Change in methodology and techniques should be implemented. All the language skills are vital and should be given equal importance. The sense of balanced approach should be adopted while conducting and organizing the events and activities for language skills. School level plays an important role in developing attitudes and learning, should be considered for researching ER and reading areas.

\section{References}

1. Camiciottoli, B. C. (2001). Extensive reading in English: Habits and attitudes of a group of Italian university EFL students. Journal of Research in Reading,

2. Chang, A. C-S, \& Renandya, W. (2017). Current practice of extensive reading in Asia: Teachers' perceptions. The Reading Matrix, 17(1), 40 -58.

3. Chien, C. And Yu, K. (2015).Applying extensive reading to improve unmotivated learners ${ }^{\star}$ attitudes toward reading in English. International Journal of Learning, Teaching and Educational Research. 13, (2), 1-25

4. Day, R. R., \& Bamford, J. (1998). Extensive reading in the second language classroom. Cambridge: Cambridge University Press.

5. Fishbein, M., \& Ajzen, I. (1975). Belief, attitude, intention, and behavior: An introduction to theory an research. Reading, MA: Addison-Wesley.

6. Grabe, W., \& Stoller, F. L. (2002). Teaching and researching reading. Malaysia.

7. Greaney, V . (1980). Factors related to amount and type of leisure time reading: Reading Research Quarterly, 15(3), pp.337-57.

8. Hardy, J. E. (2016). The effects of a short-term extensive reading course in Spanish. Journal of Extensive Reading, 4(2), 47-68.

9. Jacobs, D. M., \& Gallo, P. (2002). Reading alone together: Enhancing extensive reading via student-student cooperation in second language instruction. Reading Online, 5(6). Retrieved from http://www.readingonline.org/articles/art

10. Kamhieh, C. (2012). The leisure reading habits of first-year, female Emirati university students: An investigation Doctoral thesis, Cantebury: Christ Church University.

11. Krashen, S. D. (2004). Free voluntary reading: New research, applications, and controversies. Proceedings of the Fifth Pan-Asian Conference on Language Teaching at FEELTA2004, Vladivostok, June 24-27. 2004, 16-19.

12. Lao, C. Y. \& Krashen, S. (2000). The impact of popular literature study on literacy development in EFL: More evidence for the power of reading. System, 28, 261-270.

13. McKenna, M. C. (1994). Toward a model of reading attitude acquisition. In E. H. Crammer \& M. Castle (Eds.), Fostering the love of reading: The affective domain in reading education (pp.18-40). Newark, DE: International Reading Association.

14. Memon, S. (2014). Reading attitudes in L1 and L2 among rural and urban learners in a Pakistani context (PhD thesis). University of Bedfordshire, Bedfordshire. from http://hdl.handle.net/10547/576434 [Google Scholar]

15. Nuttall, C. (1982; new edition 1996).Teaching reading skills in a foreign language. Oxford: Heinemann Educational Books.

16. Nuttall, C. (2005). Teaching reading skills in a foreign language. Oxford, UK: Macmillan Education. Nye, P. W., \& Fowler, C. A. (2003). Shadowing latency and imitation: The effect of familiarity with the phonetic patterning of English. Journal of Phonetics, 31, 63-79.

17. Park, A Young. 2017. A comparison of the impact of extensive and intensive reading approaches on the Korean EFL learners' reading rate and reading comprehension development. International Journal of Applied Linguistics \& English Literature

18. Robb, T. \& Kano, M. (2013). Effective extensive reading outside the classroom: A large-scale experiment. Reading in a Foreign Language 25(2), 234-247. development in EFL: More evidence for the power of reading. System, 28, 261-270. doi:10.1016/s0346- 251x(00)00011-7.

19. Robb, T. N., \& Susser, B. (1989). Extensive reading vs skills building in and EFL context. Reading in a Foreign Language, 5, 239-51

20. Ro, E. and Chen, C-L. A. (2014). Pleasure Reading behaviour and attitude of non-academic ESL students: A Replication Study. Reading in a Foreign Language, 26(1), 49-72.

21. Ro, E, (2013), A case study of extensive reading with an unmotivated L2 reader. Reading in a Foreign Language, 25, 212-233.

22. Strauss, S., Calero, C. I., \& Sigman, M. (2014). Teaching, naturally. Trends in Neuroscience and Education.

23. Yamashita, J. (2013). Effects of extensive reading on reading attitudes in a foreign language. Reading in a Foreign Language, 25, 234-247. 